\title{
Isolation of a Yeast Artificial Chromosome Clone That Spans the (12;16) Translocation Breakpoint Characteristic of Myxoid Liposarcoma
}

\author{
Robert M. Gemmill, Michael J. Mendez, Cynthia M. Dougherty, \\ Sylvie Paulien, Martha Liao, Deanna Mitchell, \\ Sheryl A. Jankowski, Jeffrey M. Trent, Carol Berger, \\ Avery A. Sandberg, and Paul S. Meltzer
}

\begin{abstract}
Cytogenetic analysis of liposarcomas has demonstrated that translocation (12;16) (q13.3;p11.2) is characteristic of the myxoid subtype of this adipose tissue tumor. Our previous results suggested that the GLI gene is close to the translocation breakpoint on chromosome 12. We now describe a yeast artificial chromosome (YAC) that contains GLI and spans the chromosome 12 region involved in the $\mathrm{t}(12 ; 16)$ breakpoint. This clone will permit rapid definition of the genetic region surrounding the breakpoint and allow isolation of the gene presumably affected by the translocation.
\end{abstract}

\section{INTRODUCTION}

Both malignant and benign adipose tissue tumors [1, 2], as well as other soft tissue tumors [3] are frequently characterized by aberrations in chromosome bands $12 q 13-14$. These observations suggest that the $12 \mathrm{q} 13-14$ region contains genes critical to neoplastic development of many soft tissues. Myxoid liposarcoma (MLPS), a relatively low-grade sarcoma of adipose tissue origin, is characterized by the specific rearrangement $t(12 ; 16)(q 13.3 ; p 11.2)[1,4-7]$. This translocation, shown in Figure 1, has been observed in most MLPS cases reported to date. The consistent presence of this rearrangement in MLPS suggests that one or more genes located at the reciprocal breakpoints are causally related to either development or progression of this tumor. Isolation of the translocation breakpoint region characteristic of MLPS would provide access to these genes and permit an understanding of the molecular basis for this disease, and could also determine whether this chromosomal region is causally related to other soft tissue tumors.

From the Eleanor Roosevelt Institute, Denver, Colorado, Departments of Pediatrics (D. M., P. S. M.) Human Genetics (R. M. G., S. P., C. M. D., M. J. M., M. L., S. A. J.), Radiation Oncology (P. S. M., J. M. T.) and Genetics (J. M. T.), University of Michigan Medical School, Ann Arbor, Michigan, and Southwest Biomedical Research Institute (A. A. S., C. B.), Scottsdale, Arizona.

Dr. Sylvie Paulien's present address is C.E.P.H., Paris, France.

Dr. Mendez's present address is CellGenesys Inc., Foster City, California.

Address reprint requests to: Dr. Robert M. Gemmill, Eleanor Roosevelt Institute, Denver, CO, 80206.

Received July 29, 1992; accepted August 12, 1992

166

Cancer Genet Cytogenet 62:166-170 (1992)

$0165-4608 / 92 / \$ 05.00$
Analysis of the genomic region surrounding the zincfinger gene GLI $[8,9]$, previously mapped to $12 \mathrm{q} 13.3-\mathrm{q} 14.1$ $[10,11]$, suggested that the $12 ; 16$ breakpoint was nearby [12]. We now describe the isolation of a yeast artificial chromosome (YAC) clone containing GLI and demonstrate that this clone extends across the 12;16 translocation breakpoint region of human chromosome 12 .

\section{MATERIALS AND METHODS}

Clone Isolation and Analysis

Probes were labeled with ${ }^{32} \mathrm{P}$-dCTP by the random priming method [13] after being excised from agarose gels. The GLI probe pKK36P1 [8] was used to screen a total human YAC library [14] as previously described [15]. Positive addresses were determined by colony hybridization; YACs were then purified by streaking for single colonies on minimal agar plates. Purified yeast colonies were grown in rich liquid medium, imbedded in agarose blocks, and analyzed on pulsed-field gels. DNA isolated from the confirmed GLIpositive YAC strain (100C4) was subcloned into $\lambda$ FIX II (Stratagene, LaJolla, CA) after partial Mbol digestion and partial fill-in of the GATC overhang to prevent coligation events. Human $\lambda$ subclones (approximately 150) were identified by plaque hybridization using a human repetitive sequence probe. Subclones $1 \mathrm{~A} 5$ and $2 \mathrm{C} 6$ were identified during a $\lambda$ walking procedure beginning at the right (URA) end of 100C4 and proceeding to GLI.

Fluorescence In Situ Hybridization (FISH) Analysis The 100C4 YAC was biotinylated by nick translation according to the manufacturer's instructions (BRL, Gaithersburg, MD) and recovered by ethanol precipitation. FISH 
was performed according to the method of Pinkel et al. [16]. For whole chromosome painting (WCP) experiments, either biotinylated or Spectrum Orange-labeled probes were hybridized and visualized according to the standard Imagenetics protocol (WCPs, Imagenetics, Naperville, IL). FISH experiments were examined and photographed using a Zeiss Axiophot fluorescence microscope (Thornwood, NY), equipped with a fluorescein/rhodamine dual bandpass filter. MLPS metaphases were harvested and trypsin G-banded as previously described [17].

\section{RESULTS}

\section{Isolation of a YAC Clone Containing the GLI Gene}

The total human YAC library developed by Albertsen et al. [14] was screened for GLI homologous YACs by our Southern blot hybridization strategy [15]. This library contains approximately 50,000 clones with a 400 -kilobase (kb) average insert size representing about seven genome equivalents. One four-plate pool contained a YAC of about $390 \mathrm{~kb}$ that was homologous to the GLI probe pKK36P1. This YAC (100C4) was purified and shown by hybridization analysis to contain both GLI probes, pKK36P1 and pKK380 (Fig. 2).

\section{FISH Analysis Shows that the GLI YAC Spans the 12;16 Breakpoint}

FISH experiments were performed to determine whether 100C4 crossed the 12;16 translocation breakpoint. Figure 3 shows metaphase spreads prepared from myxoid liposarcoma (MLPS) case no. ST-88-11172 [12] after several different banding or FISH treatments. G-banding (Fig. 3A) demonstrated that this case contained the characteristic translocation $(12 ; 16)(q 13.3 ; \mathrm{p} 11.2)$ in $100 \%$ of 20 metaphases examined. These results were confirmed by FISH with WCP probes (Fig. 3B). In this painting experiment,

Figure 1 Translocation (12;16)(q13.3;p11.2) in myxoid liposarcoma. Normal chromosomes 12 and 16 are shown with breakpoints (arrows) together with the reciprocal translocation products. The der(12) chromosome is retained in the ML5-12 hybrid.

$t(12 ; 16)(q 13.3 ; p 11.2)$ in Myxoid Liposarcoma

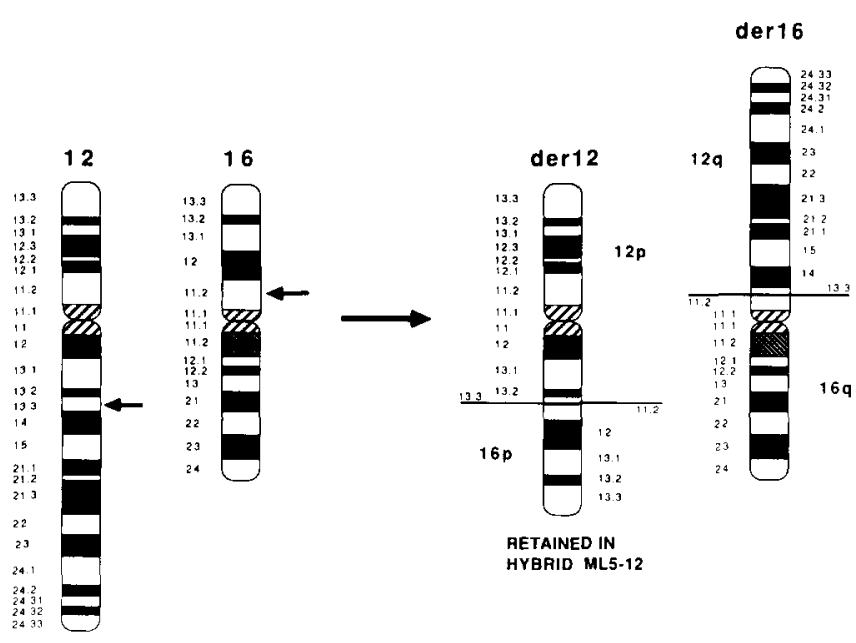

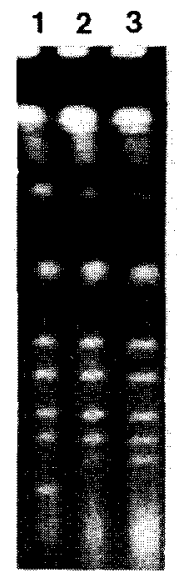

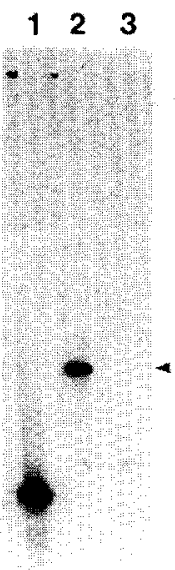

pKK36P1 $\begin{array}{lll}1 & 2 & 3\end{array}$

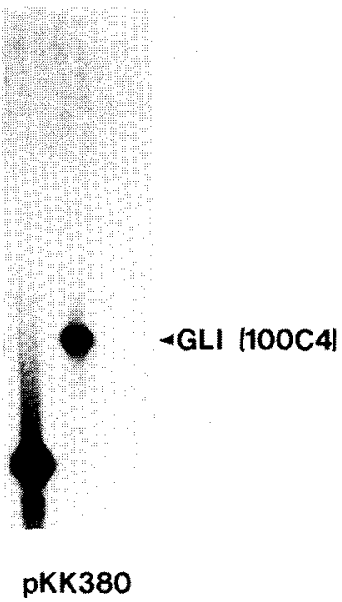

Figure 2 Isolation of the GLI containing yeast artificial chromosome (YAC) 100C4. Ethidium bromide-stained pattern of yeast chromosomes in three YAC-bearing strains (left). Lane 1: 118D2, a small YAC containing GLI sequences isolated from the Washington University YAC library [20]. Lane 2: 100C4 YAC (arrow). Lane 3: an unrelated control YAC strain. The samples were separated on a pulsed-field gel using a 50-second pulse time at $5 \mathrm{~V} / \mathrm{cm}$ for 24 hours. A Southern blot prepared from this gel was hybridized sequentially with the indicated GLI-specific probes (middle and right panels).

the biotinylated chromosome 12 probe is visualized with fluorescein, generating a green signal, while the chromosome 16 probe is directly labeled with a fluorochrome (Spectrum Orange, Imagenetics) which yields a red/orange signal. Bicolor FISH experiments (Fig. 3C) were performed to map the $100 \mathrm{C} 4 \mathrm{YAC}$ with respect to the chromosome 12 breakpoint. Biotinylated YAC DNA was visualized with fluorescein (yellow-green signal), and the WCP for chromosome 12 was labeled with Spectrum Orange (red-orange signal). In addition to the YAC hybridization signal observed on the normal chromosome 12 , specific hybridization was visualized on both the der(12) and der(16) chromosomes at the border between chromosome 12 and 16 sequences. The cell shown in Figure $3 \mathrm{C}$ had undergone endoreduplication, and the corresponding duplication of the hybridization signal confirmed its specificity. Although the hybridization signal on the $\operatorname{der}(16)$ was weaker than that observed on the der(12), it was highly reproducible. Additional examples of hybridization to these chromosomes are shown in Figure 3D, further supporting the conclusion that the GLI YAC contains sequences that span the $\mathrm{t}(12 ; 16)$ breakpoint.

\section{The 100C4 YAC Crosses the 12;16 Breakpoint Present in a Somatic Cell Hybrid}

We developed a somatic cell hybrid (ML5-12) that retains the derivative 12 chromosome from a MLPS (case no. ST88-13233 [12]) but does not contain either normal 12 or derivative 16 sequences (M. Liao, unpublished observations). This hybrid retains GLI gene sequences (Fig. 4, right 


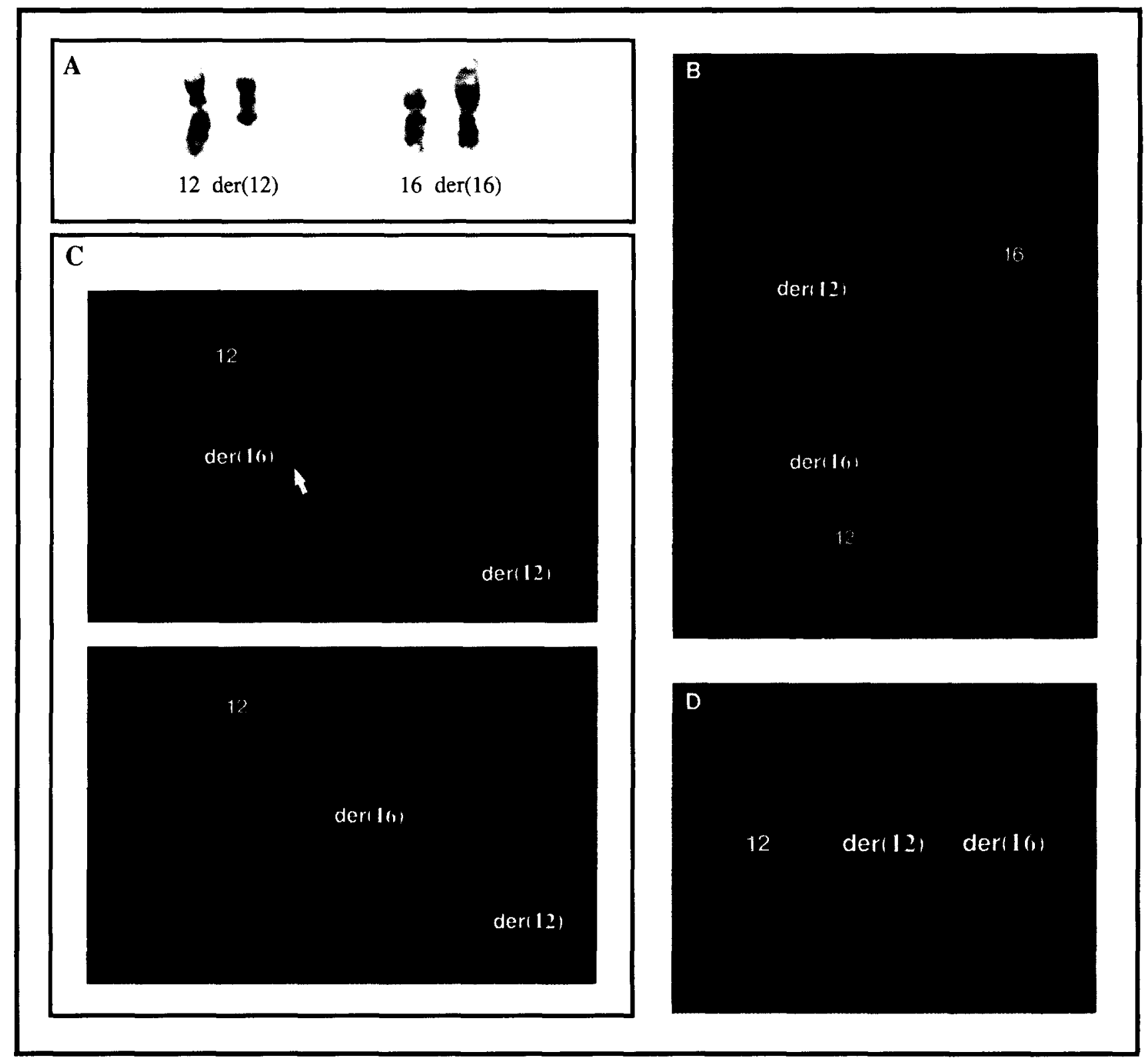

Figure 3 Fluorescence in situ hybridization (FISH) analysis of $t(12 ; 16)$ chromosomes from myxoid liposarcoma (MLPS) case ST-88-11172 using the 100C4 YAC. (A) Representative trypsin G-banded chromosomes showing the normal homologues of chromosomes 12 and 16 and the reciprocal translocation $(12 ; 16)(\mathrm{q} 13.3 ; \mathrm{p} 11.2)$. (B) Partial metaphase hybridized with whole chromosome probes for chromosome 12 (yellow-green) and chromosome 16 (red-orange) showing the normal and translocated derivatives of these chromosomes. (C) Partial metaphase with endoreduplication visualized by DAPI staining (top) and bicolor FISH (bottom) using a whole chromosome probe for chromosome 12 (red-orange) and the 100C4 yeast artificial chromosome (YAC) (yellow-green). The YAC hybridization signal is apparent on the normal 12, the der(12) and der (16) chromosomes. (D) Examples of the normal 12, $\operatorname{der}\{12)$ and $\operatorname{der}(16)$ from two additional cells showing hybridization of $100 \mathrm{C} 4$ to both sides of the $(12 ; 16)(q 13.3 ; \mathrm{p} 11.2)$ translocation breakpoint. 


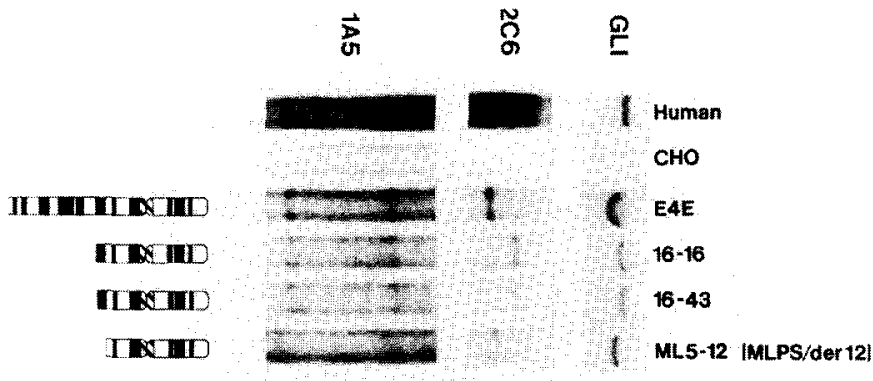

Figure 4 Proximal/distal mapping of subclones from $100 \mathrm{C} 4 \mathrm{con}$ firms that the yeast artificial chromosome (YAC) spans the $t(12 ; 16)$ breakpoint. DNA samples from 6 cell lines [one normal human fibroblast line (human), hamster parental line CHO-K1 (CHO), monochromosomal 12 hybrid $\mathrm{E} 4 \mathrm{E}$ ( $\mathrm{E} 4 \mathrm{E}$ ), two radiation reduction hybrids (16-16 and 16-43), and the ML5-12 hybrid which retains the der(12) chromosome from a myxoid liposarcomal were digested with EcoRI, separated on an agarose gel, and used to prepare Southern blots. The chromosome 12 content of the four hybrid cell lines is diagrammed at the far left. The hybrid panels were hybridized with probes specific for GLI and the two 100C4 subclones, 2C6 and 1A5, as indicated.

panel), demonstrating that GLI is proximal to the $12 ; 16$ breakpoint, at least in the case from which the hybrid was made. Subclones of 100C4, prepared in the phage vector $\lambda$ FIX II, were tested for localization with this hybrid along with a panel of additional chromosome 12-specific hybrids [18]. Results demonstrate that the subclone 2C6 (Fig. 4, middle) contains chromosome 12 sequences proximal to the breakpoint whereas $1 \mathrm{~A} 5$ sequences (Fig. 4, left) are distal, confirming that the chromosome 12 region contained in the 100C4 YAC spans the 12;16 breakpoint.

\section{DISCUSSION}

Our results show that the $100 \mathrm{C} 4$ YAC contains DNA sequences derived from the q13 region of human chromosome 12 , including the GLI gene and that these sequences span the 12;16 breakpoint characteristic of MLPS. FISH analysis demonstrated hybridization signals to the chromosome 12 portion of both derivative chromosomes at positions immediately adjacent to the translocation breakpoint. The weaker FISH signal on the der(16) chromosome could result if the breakpoint position in the $100 \mathrm{C} 4$ YAC were close to one end. Preliminary restriction mapping data for the 100C4 YAC (not shown) suggests that this is correct. The hybrid panel results show that the subclone $1 \mathrm{~A} 5 \mathrm{de}-$ rives from a small segment of $12 \mathrm{q}$, distal to the $t(12 ; 16)$ breakpoint and between $q 13.3$ and $q 14.3$. This same panel shows that the 2C6 subclone arises from the region proximal to the 12q13.3 breakpoint. Although the hybrid panel used did not differentiate the $\mathrm{q} 13.3 \rightarrow$ pter region, that GLI has been previously mapped to q13.3 suggests that all the chromosome 12 sequences present in the 100C4 YAC derive from a contiguous region located at 12q13.3. In support of this notion, preliminary pulsed-field gel data show that the 1A5- and 2C6-derived probes, which flank the break- point, are physically linked to each other and to GLI in genomic DNA (data not shown).

Isolation of the YAC clone we described will now permit identification of sequences immediately flanking the breakpoint, including any that may encode a gene. Furthermore, these sequences will permit walking from chromosome 12 across the breakpoint onto chromosome 16 to isolate any transcription unit from this chromosome that may be involved. The consistent nature of the translocation, with respect to both reciprocal breakpoints and phenotype of the sarcoma, suggest that specific genes on both chromosomes must be interrupted to generate this tumor. Although a chimeric gene, analogous to the BCR-ABL gene in CML [19], probably results from this rearrangement, regulatory alterations may be a significant factor. The phenotype of MLPS cells, apparently arrested during the preadipocyte stage of development, suggests that one or both of these genes may play a critical role during adipocyte differentiation.

The authors thank Drs. Denis Le Paslier and Daniel Cohen for providing the C.E.P.H. human YAC library and Dr. Bert Vogelstein for providing the GLI probes. This study was supported in part by Program Project grant No. CA-41183 and by Grant No. CA-56725 to P. S. M. from the National Institutes of Health. In addition, this work was supported by a grant from the Colorado Cancer League to R. M. G., by a grant from Amoco Technology, Naperville, IL to P. S. M. and by a grant from the American Foundation for AIDS Research to M. L. The expert technical assistance of Ann Burgess, Tom Dennis, and Efang Li is gratefully acknowledged.

\section{REFERENCES}

1. Turc-Carel C, Limon J, Dal Cin P, Rao U, Karakousis C, Sandberg AA (1986): Cytogenetic studies of adipose tissue tumors. II. Recurrent translocation $t(12 ; 16)(q 13 ; p 11)$ in myxoid liposarcomas. Cancer Genet Cytogenet 23:291-299.

2. Sreekantiah C, Leong SPL, Karakousis CP, McGee DL, Rappaport WD, Villar HV, Neal D, Fleming S, Wankel A, Herrington PN, Carmona R, Sandberg AA (1991): Cytogenetic profile of 109 lipomas. Cancer Res 51:422-433.

3. Heim S, Nilbert M, Vanni R, Floderus U-M, Mandhal N, Liedgrns S, Lecca U, Mitelman F (1988): A specific translocation, $\mathrm{t}(12 ; 14)(\mathrm{q} 14-15 ; \mathrm{q} 23-24)$, characterizes a subgroup of uterine leiomyomas. Cancer Genet Cytogenet 32:13-17.

4. Smith S, Reeves BV, Wong L (1987): Translocation $t(12 ; 16)$ in a case of myxoid liposarcoma. Cancer Genet Cytogenet 26:185-186.

5. Mertens F, Johansson B, Mandhal N, Heim S, Rydholm A, Willen H, Mitelman F (1987): Clonal chromosome abnormalities in two cases of liposarcoma. Cancer Genet Cytogenet 28:137-144

6. Eneroth M, Mandahl N, Heim S, Willen H, Rydholm A, Alberts KA, Mitelman F (1990): Localization of the chromosomal breakpoints of the $t(12 ; 16)$ in liposarcoma to subbands 12q13.3 and 16p11.2. Cancer Genet Cytogenet 48:101-107.

7. Molenaar WM, Dejong B, Buist J, Idenburg VJS, Seruca R, Vos AM, Hoekstra HJ (1989): Chromosomal analysis and the classification of soft tissue sarcomas. Lab Invest 60:266-274.

8. Kinzler KW, Bigner SH, Bigner DD, Trent JM, Law ML, O'Brien SJ, Wong AJ, Vogelstein B (1987): Identification of an amplified, highly expressed gene in a human glioma. Science 236:70-73. 
9. Kinzler KL, Ruppert JM, Bigner SH, Vogelstein B (1988): The GLI gene is a member of the Kruppel family of zinc-finger proteins. Nature 332:371-374.

10. Arheden K, Ronne M, Mandahl N, Heim S, Kinzler KW, Vogelstein B, Mitelman F (1989): In situ hybridization localizes the human putative oncogene GLI to chromosome subbands 12q13.3-14.1. Hum Genet 82:1-2.

11. Dal Cin P, Turc-Carel C, Sandberg AA, Van Den Berghe H (1989): More precise localization of GLI gene by in situ hybridization. Cytogenet Cell Genet 51: Human Gene Mapping 10, p 982 (A2536).

12. Paulien S, Turc-Carel C, Dal Cin $P$, Jani-Saot $S$, Sreelamtaiah C, Leong S, Vogelstein B, Kinzler KW, Sandberg AA, Gemmill RM (1990): Myxoid liposarcoma with t(12;16)(q13;p11) contains site-specific alterations in methylation patterns surrounding a zinc-finger gene mapped to the breakpoint region on chromosome 12. Cancer Res 50:7902-7908.

13. Feinberg AP, Vogelstein B (1984): A technique for radiolabeling DNA restriction fragments to high specific activity. Addendum. Anal Biochem 137:266-267.

14. Albertsen HM, Abderrahim H, Cann HM, Dausset J. Le Paslier D, Cohen D (1990). Construction and characterization of a yeast artificial chromosome library containing seven haploid human genome equivalents. Proc Natl Acad Sci USA $87: 4256-4260$.

15. Mendez MJ, Klapholz S, Brownstein BH, Gemmill RM (1991): Rapid screening of a YAC library by pulsed-field gel Southern blot analysis of pooled YAC clones. Genomics 10:661-665.

16. Pinkel D, Landergent J, Collins C, Fuscoe J, Segraves R, Lucas J, Gray J (1988). Fluorescence in situ hybridization with human chromosome-specific libraries: Detection of trisomy 21 and translocation of chromosome 4. Proc Natl Acad Sci USA 85:9138-9142.

17. Trent JM, Thompson FH (1987): Methods for chromosome banding of human and experimental tumors in vitro. Methods Enzymol 151:267-279.

18. Law ML, Tung L, Morse HG, Berger R, Jones C, Cheah KSE, Solomon AE (1986): The human type II collagen gene (COL2A1) assigned to 12q14.3. Ann Hum Genet 50:131-137.

19. Daley GQ, Ben-Neriah Y (1991): Implicating the bcr/abl gene in the pathogenesis of Philadelphia chromosome-positive human leukemia. Adv Cancer Res 57:151-184.

20. Brownstein BH, Silverman GA, Little RD, Burke DT, Korsmeyer SJ, Schlessinger D, Olson MV (1989): Isolation of singlecopy human genes from a library of yeast artificial chromosome clones. Science 244:1348-1351. 